\title{
Assessment of central venous catheters applied in pediatric patients at emergency department
}

\author{
Yılmaz Zengin*, Mustafa İçer, Ercan Gündüz, Recep Dursun, Hasan Mansur Durgun, Cahfer Güloğlu \\ Department of Emergency Medicine, Faculty of Medicine, Dicle University, Diyarbakır, Turkey
}

\section{ARTICLE INFO}

\section{Article History}

Received

$11 / 10 / 2013$

Accepted $25 / 10 / 2013$

\section{* Correspondence to: \\ Y1lmaz Zengin \\ Department of Emergency Medicine, \\ Faculty of Medicine, \\ Dicle University, \\ Diyarbakır, Turkey \\ e-mail: yilmazzengin79@mynet.com}

\section{Keywords:}

Central venous catheterization

Complication

Emergency department

Pediatric patient

\author{
ABSTRACT
}

Central venous catheterization, an effective method for intravenous therapy, is commonly used at emergency departments and intensive care units. In this study, we aimed to assess the complications of central venous catheterization procedure in pediatric patients at emergency department and to seek possible risk factors for complications. This study included a total of 64 patients (41 males $(64.1 \%)$ and 23 females (35.9\%)) who underwent central venous catheterization between January 1, 2011 and May 31, 2013. Personal records of the patients were retrospectively assessed using the hospital records system. A total of 64 catheters [53 (\%82.8) femoral, $5(\% 7.8)$ subclavian, and $6(\% 9.4)$ jugular] were inserted in all cases. One arrhythmia episode, one pneumothorax, five arterial punctures, and 4 hematomas were observed, making up a total of 11 complications (17.2\%). No statistically significant relationship was observed between development of complications and age, gender, indication for central venous catheterization, anatomical site preferred for catheter insertion, time of the day of performance of the procedure, and the level of training of the performing resident $(\mathrm{p}>0.05)$. Hypovolemic shock as an indication for the procedure and three or more attempts to access target vein during insertion were significantly correlated with complications $(\mathrm{p}=0.015$ and $\mathrm{p}=0.025$, respectively). Three or more attempts to access the target vein, as well as hypovolemic shock as an indication of the procedure, were risk factors for complications.

J. Exp. Clin. Med., 2013; 30:345-348

\section{Introduction}

Central venous catheterization (CVC), an effective method for intravenous therapy, is a very important minor surgical procedure performed at emergency departments and intensive care units for infusion of drugs and blood products, central venous pressure monitoring, emergency hemodialysis treatment, and management of complicated cases with prolonged hospital stay requiring a large-bore IV line (Karapınar and Cura, 2007).

The three most commonly used sites used for CVC insertion in children are femoral (FV), subclavian (SCV), and internal jugular (IJV) veins. Technical difficulties and complications of CVC are particularly more common in children.
Complications related with $\mathrm{CVC}$ are divided into 3 groups as mechanical, thrombotic, and infectious complications (Çitak et al., 2002). Among these, pneumothorax, hemothorax, air embolism, nerve injuries, arrhythmias, catheter malposition, catheter retraction, and arterial punctures may be observed at acute period during the procedure (Moral and Uyar, 2005.). Operator experience and skill, site of catheter insertion, and various other risk factors affect the number and severity of such complications (Randolph et al., 2005).

With this study, we aimed to contribute to the literature by investigating demographics of children undergoing CVC procedure and type and rate of complications that occur during or after this procedure at emergency departments. 


\section{Materials and method}

This study retrospectively assessed patient records of 64 pediatric patients who underwent CVC procedure at the Emergency Department of Dicle University Hospital between January 1, 2011 and May 31, 2013. Patient age, gender, diagnosis, indication for CVC procedure, previous CVC history, catheter diameter, initial insertion site, number of attempts required to access the vein, time of the day of performance of the procedure, level of training of the performing physician, site of CVC procedure, complications, duration of catheter in place, and the clinic of admission were recorded for analysis.

All catheters were placed by residents using the Seldinger technique under the supervision of an expert physician. All patients received preprocedural sedation $(0.1 \mathrm{mg} / \mathrm{kg}$ intravenous midazolam) and analgesia ( $1 \mu \mathrm{g} / \mathrm{kg}$ intravenous fentanyl). The patients were monitored for heart rate and rhythm, respiratory rate, and oxygen saturation before CVC procedure. Local anesthesia was achieved using lidocaine HCL ampul. Selection of catheterization site (FV, SCV, or IJV) was left at the physician discretion. However, the subclavian route was not preferred in presence of a bleeding diathesis. A 4 Fr double-lumen temporary catheter was placed in patients weighing less than five $\mathrm{kg}, 5 \mathrm{Fr}$ in those weighing between $5-20 \mathrm{~kg}$, and $7 \mathrm{Fr}$ in those weighing more than $20 \mathrm{~kg}$. Appropriate aseptic and antiseptic measures were taken per hospital protocol, and operators properly washed their hands prior to procedure. Sterilization of the surgical field was achieved by liberal use of $10 \%$ povidone iodine solution.

All patients who underwent CVC procedure had a chest $\mathrm{X}$-ray after the procedure to verify that the catheter tip lies between superior vena cava and right atrium in SCV and IJV catheters, and in inferior vena cava in FV catheters. In addition, patient examination, noninvasive monitoring, and evaluation of chest X-Ray were performed to exclude or diagnose acute complications of the procedure such as hematoma formation, arrhythmias, pneumothorax, hemothorax, and catheter malposition. Patient records of all admitted patients were retrospectively reviewed for CVC-related complications and duration of catheter in place.

The patients were divided into 2 groups as those without any complication (Group 1, n=53) and those with a complication (Group 2, $\mathrm{n}=11$ ). Patients who experienced pneumothorax, hemothorax, hydrothorax, chylothorax, arterial injury, nerve injury, arteriovenous fistula formation, arrhythmia, air embolism, heart laceration, hematoma, phlebitis, catheter malposition, and catheter infection after $\mathrm{CVC}$ procedure were included in Group 2.

Patient age, gender, indication for $\mathrm{CVC}$ procedure, catheter diameter, the first preferred insertion site, site of CVC procedure, number of attempts required to access the vein, time of the day of performance of the procedure, level of training of the performing physician were evaluated with respect to their potential of resulting in complications in the Group 1 and Group 2.

Statistical analysis was performed using SPSS version 15.0 (SPSS Inc., Chicago, IL, USA). Data were tested for normality using the Kolmogorov-Smirnov normality test. The results were expressed as means \pm SD or number of patients. Categorical data were analyzed using the chi-squared test. Student's t-test was used for normally distributed data. A P-value of $<0.05$ was considered statistically significant.

\section{Results}

In this study, $41(64.1 \%)$ of 64 patients were male and 23 $(35.9 \%)$ were female. Of 64 patients in whom a CVC procedure was carried out, 11 (17.2\%) experienced a complication. The distribution of complications by central venous catheter localization is given in Table 1.

\begin{tabular}{|c|c|c|c|c|}
\hline Complications & $\begin{array}{c}\text { Femoral vein } \\
\mathbf{n}(\%)\end{array}$ & $\begin{array}{c}\text { Internal } \\
\text { jugular } \\
\text { vein } \\
\text { n(\%) } \\
\end{array}$ & $\begin{array}{c}\text { Subclavian } \\
\text { vein } \\
\text { n(\%) }\end{array}$ & $\begin{array}{l}\text { Total } \\
\text { n(\%) }\end{array}$ \\
\hline Arterial puncture & $5(7.8)$ & $0(0.0)$ & $0(0.0)$ & $5(7.8)$ \\
\hline Hematoma & $3(4.7)$ & $1(1.6)$ & $0(0.0)$ & $4(6.3)$ \\
\hline Pneumothorax & $0(0.0)$ & $0(0.0)$ & $1(1.6)$ & $1(1.6)$ \\
\hline Arrhythmia Episode & $0(0.0)$ & $1(1.6)$ & $0(0.0)$ & $1(1.6)$ \\
\hline Total & $8(12.5)$ & $2(3.2)$ & $1(1.6)$ & $11(17.3)$ \\
\hline
\end{tabular}

The mean age was $122.00 \pm 58.117(37-187)$ months in Group 2 and 115.43 \pm 55.223 (24-191) months in Group 1. Of 11 patients who developed a complication, 7 (10.9\%) were male and $4(6.3 \%)$ were female. There was no significant relationship between development of complications and gen$\operatorname{der}(\mathrm{p}=0.614)$.

The analysis of factors responsible for complications of CVC procedure and their effect on complications are given in Table 2. According to this table, the most common indication for CVC procedure was hypovolemic shock which was present in 27 (42.2\%) patients (Table 2). Presence of hypovolemic shock as an indication for central venous catheter insertion was significantly related with complication development $(\mathrm{p}=0.015)$. In addition, three or more attempts were made to access the vein in $22(34.4 \%)$ patients (Table 2). Three or more attempts for access the vein was also significantly related with complication development $(\mathrm{p}=0.025)$.

The mean duration of catheter in place was 9.00 \pm 7.73 $(0-20)$ days in the group with complications (Group 1) and $8.22 \pm 6.44$ days in the group without any complications (Group 2); neither of the groups was different with respect to duration of catheter in place.

\section{Discussion}

CVC procedure plays a critical role especially in management of patients at emergency departments. It is preferentially favored in resuscitation of emergency patients since it is rapidly and readily carried out by experienced physicians and it allows extracorporeal treatments including hemodynamic monitoring, plasmapheresis, and hemodialysis, and, finally, it also provides a suitable intravenous line (Akyıldız et al., 2009). Seldinger technique is the generally accepted technique for insertion of a central venous catheter (Seldinger, 1953).

Although CVC procedure is a more difficult and risky procedure in children compared to adults, it is safe when performed by experienced operators (Karapınar and Cura, 2007). In our study, all attempts for catheter insertion were successful. Switch of catheter site was required only in cases with hematoma formation. We believe that this high success rate was a result of appropriate conditions under which CVC procedure was performed and insertion of all catheters by a 
2-year senior resident under the supervision of an emergency department physician.

Dheer et al. reported that the most common indication for insertion of a central venous catheter was the absence of adequate peripheral veins (Dheer et al., 2011) while Anıl et al. reported that the most common indication was the requirement of adequate fluid resuscitation and administration of treatments directed at shock (Anıl et al., 2011). We, on the other hand, identified that the most common indication was hypovolemic shock. The success rates may have been lower and complication rates may have increased in hypovolemic due to a more difficult access to the vein owing to a low venous pressure.

There are some advantages and disadvantages of various entry sites for CVC (Çitak et al., 2002). A 276-patient study made by Akyıldız et al., in which $79.7 \%, 17.1 \%$, and $3.2 \%$ of the patients underwent a CVC procedure involving $\mathrm{SCV}, \mathrm{FV}$, and IJV, respectively, reported that SCV was more suitable for prolonged catheterization owing to low rates of colonization and infection (Akyıldız et al., 2009). However, Anıl et al., in a study in which $128 \mathrm{CVC}$ procedures involving $\mathrm{FV}$ in $68.8 \%, \mathrm{SCV}$ in $28.9 \%$, and IJV in $2.3 \%$ were carried out, recommended use of FV route due to easier access, guidance of the procedure by femoral pulse, a more readily achieved hemostasis even when arterial puncture occurs, lack of impedance with cardiopulmonary resuscitation, and absence of hemo- or pneumothorax (Anil et al., 2011). Also in our study, primary preference was given to $\mathrm{FV}$, which we think can be more easily and rapidly accessed.

A more widespread use of CVC procedure leads to an increase in catheter-related complications (Bhatt et al., 2012). The early complications related to CVC procedure are arterial puncture, hematoma formation, nerve injury, pneumothorax, hemothorax, difficulty cannulating the vein, and arrhythmias (Seldinger, 1953). In literature, the complication rates related to CVC range between 0.3 and 22\% (Sheridan and Weber, 2006). Anil et al. reported a total of 6 (4.7\%) complications, namely two hematomas, two arterial punctures, one arrhythmia, and one pneumothorax (Anıl et al., 2011). Our complication rate was also in agreement with the literature, and it was contributed to the experience of the performing medical team, as well as use of adequate sedation and analgesia in all patients.

Literature data indicate that rates of arterial puncture and hematoma formation during CVC procedure are 1.9-12.8\% and 1.4-5.2\%, respectively (Karapınar and Cura, 2007; Çitak et al., 2002; Sheridan and Weber, 2006). Our rate of arterial puncture was similar to the literature. Arterial punctures

Table 2. The analysis of factors responsible for complications of CVC procedure and their effect on complications in Group 1 and Group 2

\begin{tabular}{|c|c|c|c|c|}
\hline & $\begin{array}{c}\text { Group1 Complication (-) } \\
\mathbf{n}(\%)\end{array}$ & $\begin{array}{c}\text { Group2 Complication (+) } \\
\mathbf{n}(\%)\end{array}$ & Total n(\%) & $\mathbf{P}$ \\
\hline \multicolumn{5}{|l|}{ Gender } \\
\hline Male & $34(82.9)$ & $7(17.1)$ & $41(64.1)$ & \\
\hline Female & $19(82.6)$ & $4(17.4)$ & $23(35.9)$ & 0.614 \\
\hline \multicolumn{5}{|l|}{ Indications of CVC } \\
\hline Hypovolemic shock & $26(96.3)$ & $1(3.7)$ & $27(43.2)$ & 0.015 \\
\hline CVP Monitoring & $3(100.0)$ & $0(0.0)$ & $3(4.7)$ & 0.419 \\
\hline Poor Venous Access & $10(76.9)$ & $3(23.1)$ & $13(20.5)$ & 0.528 \\
\hline Prolonged Venous Access required & $13(76.5)$ & $4(23.5)$ & $17(25.3)$ & 0.419 \\
\hline Cardio-pulmonary Resuscitation & $1(25.0)$ & $3(75.0)$ & $4(6.3)$ & 0.522 \\
\hline \multicolumn{5}{|l|}{ Catheter diameter } \\
\hline $4 \mathrm{Fr}$ & $3(100.0)$ & $0(0.0)$ & $3(4.7)$ & 0.419 \\
\hline $5 \mathrm{Fr}$ & $16(80)$ & $4(20.0)$ & $20(31.2)$ & 0.688 \\
\hline $7 \mathrm{Fr}$ & $34(82.9)$ & $7(17.1)$ & $41(64.1)$ & 0.974 \\
\hline \multicolumn{5}{|l|}{ Site of CVC procedure } \\
\hline Femoral vein & $45(84.9)$ & $8(15.1)$ & $53(82.8)$ & 0.330 \\
\hline Internal jugular vein & $4(66.7)$ & $2(33.3)$ & $6(9.4)$ & 0.862 \\
\hline Subclavian vein & $4(80.0)$ & $1(20.0)$ & $5(7.8)$ & 0.271 \\
\hline \multicolumn{5}{|l|}{ Initial insertion site } \\
\hline Femoral vein & $45(86.5)$ & $7(13.5)$ & $52(81.2)$ & 0.100 \\
\hline Internal jugular vein & $4(80.0)$ & $1(20.0)$ & $5(7.8)$ & 0.862 \\
\hline Subclavian vein & $4(57.1)$ & $3(42.9)$ & $7(11.0)$ & 0.056 \\
\hline \multicolumn{5}{|c|}{ Number of attempts required to access the vein } \\
\hline Two or less attempts & $38(90.5)$ & $4(9.5)$ & $42(65.7)$ & \\
\hline Three or more attempts & $15(68.2)$ & $7(31.8)$ & $22(34.3)$ & 0.025 \\
\hline \multicolumn{5}{|c|}{ Time of the day of performance of the procedure } \\
\hline 00:00- 06:00 & $4(100.0)$ & $0(0.0)$ & $4(6.3)$ & 0.347 \\
\hline 06:00- 12:00 & $9(90.0)$ & $1(10.0)$ & $10(15.7)$ & 0.512 \\
\hline 12:00-18:00 & $31(88.6)$ & $4(11.4)$ & $35(55.3)$ & 0.180 \\
\hline $18: 00-24: 00$ & $9(60.0)$ & $6(40.0)$ & $15(23.7)$ & 0.058 \\
\hline \multicolumn{5}{|c|}{ Level of training of the performing physician(year) } \\
\hline 1 & $9(69.2)$ & $4(30.8)$ & $13(20.5)$ & 0.146 \\
\hline 2 & 25 (80.6) & $6(19.4)$ & $31(48.0)$ & 0.656 \\
\hline 3 & $14(93.3)$ & $1(6.7)$ & 15 (23.7) & 0.217 \\
\hline 4 & $5(100.0)$ & $0(0.0)$ & $5(7.8)$ & 0.289 \\
\hline
\end{tabular}


could easily be controlled by local compression.

Literature data have shown a higher complication rate with SCV and IJV procedures compared to FV procedures (Polderman and Girbes, 2002; Rey et al., 2009). In contrast, our results demonstrated no significant difference between various venous entry sites although the majority of complications occurred during CVC procedures involving FV. We think that this is a result of fewer SCV and IJV interventions, performance of procedures involving SCV and IJV by more experienced senior residents, and sedation- and analgesia-induced reduction in technical difficulty difference between different entry sites.

The rate of complications requiring a surgical intervention has been 2-3\% in literature (Anıl et al., 2011); the most common and most serious complication during SCV catheter insertion is pneumothorax, which generally requires no intervention (Çitak et al., 2002). Our pneumothorax rate was similar to the literature, while it was managed by chest tube insertion in our study.

The incidence of new arrhythmias during $\mathrm{CVC}$ procedure has been reported as $0.3 \%$ in one report and $2.3 \%$ in another, being more common during procedures involving SCV (Sheridan and Weber, 2006; Rey et al., 2009). In contrast, our arrhythmia rates were greater with cannulation of IJV. The arrhythmias with IJV cannulation, which were considered to be a result of advancing guide wire too far into the heart, rapidly subsided with prompt withdrawal of the guide wire. No arrhythmia episodes were observed during SCV cannulation.

Late complications are related to duration of $\mathrm{CVC}$ in line, and prolongation of this time window increases both thrombotic and infectious complications. Mean length of stay in place of any central catheter should not exceed 3-4 weeks for IJV and SCV catheters, and 2 weeks for FV catheters (Akyıldız et al., 2009; Sheridan and Weber, 2006). To our opinion, lack of late-term complications in our patients is possibly related to duration of $\mathrm{CVC}$ in place as short as one week.

While some studies have shown that the success and complication rates during CVC procedures are related with patient age, weight, urgency and appropriateness of the procedure, and operator experience (An1l et al., 2011), some others have refuted the relationship between rate of complications and patient age and weight (Rey et al., 2009; Cruzeiro et al., 2006). We also did not found that complications during CVC procedure were related to patient age and operator experience. Another finding in our study was that three or more attempts for accessing the vein were significantly related to complication development. The most convenient way to decrease the number of attempts to enter the vein is to perform the procedure under the guidance of ultrasonography.

\section{Conclusion}

Technical difficulties and complications associated with CVC applications are especially common among children. On the other hand, CVC procedures are quite safe when performed by experienced operators after identification and elimination of risk factors for complications.

\section{REFERENCES}

Akyıldız, B., Kondolot, M., Akçakuş, M., Poyrazoğlu, H., Tunç, A., Hafızoğlu, D., et al. 2009. Çocuk yoğun bakım ünitesinde santral venöz kateterizasyon uygulanan hastalarımızın değerlendirilmesi: iki yıllık deneyimlerimiz. Çocuk Sağlığı ve Hastalıkları Dergisi. 52, $63-67$.

Anıl, A., Anıl, M., Kanar, B., Yavaşcan, Ö., Bal, A., Albudak, E. et al., 2011. Çocuk yoğun bakım biriminde santral venöz kateterizasyon komplikasyonlarının değerlendirilmesi. Türk Pediatri Arşivi. 46, 215-219.

Bhatt, S., Dahat, A., Jain, N., Nayak, U., Patel, V., 2012. Indications and Complications of Central Venous Catheterization in Critically ill Children in Intensive Care Unit. National Journal of Medical Research. 2, 85-88.

Cruzeiro, P.C., Camargos, P.A., Miranda, M.E., 2006. Central venous catheter placement in children: A prospective study of complications in Brazilian public hospital. Pediatr Surg Int. 22, 536-540.

Çitak, A., Karaböcüoglu, M., Üçsel, R., Uzel, N., 2002. Central venous catheters in pediatric patients-subclavian venous approach as the first choice. Pediatr Int. 44, 83-86.

Dheer, G., Chaudhry, G.K., Singh, T., 2011. Immediate complications of percutaneous central venous cannulation in children. J Indian Assoc Pediatr Surg. 16, 145-147.

Karapınar, B., Cura, A., 2007. Complications of central venous catheterization in critically ill children. Pediatr Int. 49, 593-599.

Moral, A.R., Uyar, M., 2005. Santral venöz kataterizasyon. In: Ertekin C, Taviloğlu K, Güloğlu R, et al. editors. Travma. 1st. ed. İstanbul: İstanbul Medikal Yayıncılık. p: 274-277.

Polderman, K.H., Girbes, A.J., 2002. Central venous catheter use. Part I. Mechanical complications. Intensive Care Med. 28, 1-17.

Randolph, A.G., Brun-Buisson, C., Goldmann, D., 2005. Identification of central venous catheter-related infections in infants and children. Pediatr Crit Care Med. 6, 19-24.

Rey, C., Alvarez, F., De La Rua, V., et al., 2009. Mechanical complications during central venous cannulations in pediatric patients. Intensive Care Med. 35, 1438-1443.

Seldinger, S.I.. 1953. Catheter replacement of the needle in percutaneous arteriography. Acta Radiol. 39, 368-376.

Sheridan, R.L., Weber, J.M., 2006. Mechanical and infectious complications of central venous cannulation in children: lessons learned from a 10-year experience placing more than 1000 catheters. J Burn Care Res. 27, 713-718. 